ABSTRACT: The purpose of the study was to determine whether abnormal median sensory nerve conduction among asymptomatic workers was predictive of future symptoms suggestive of carpal tunnel syndrome (CTS). This was a prospective study involving 77 workers who were identified as asymptomatic cases with electrodiagnostic findings of median mononeuropathy compared to an age- and sex-matched control group. Follow-up was completed an average of 70 months later, and subjects who reported pain, numbness, tingling, or burning in the distribution of the median nerve, based upon a hand diagram, were classified as having CTS symptoms. The followup participation rate was $70 \%$. Among subjects with abnormal median sensory latencies, $23 \%$ went on to develop symptoms consistent with CTS within the follow-up period, compared with $6 \%$ in the control group $(P=$ .010). Age and hand repetition were also risk factors for CTS, but the majority of asymptomatic workers with a median mononeuropathy do not become symptomatic over an extended time.

(C) 2001 John Wiley \& Sons, Inc. Muscle Nerve 24: 1462-1467, 2001

\title{
PROLONGED MEDIAN SENSORY LATENCY AS A PREDICTOR OF FUTURE CARPAL TUNNEL SYNDROME
}

\author{
ROBERT A. WERNER, MD, , ${ }^{1,2,3}$ NANCY GELL, ${ }^{1,3}$ ALFRED FRANZBLAU, MD, ${ }^{3,4}$ \\ and THOMAS J. ARMSTRONG, $\mathrm{PhD}^{4}$ \\ ${ }^{1}$ Department of Physical Medicine and Rehabilitation, University of Michigan \\ Medical Center, Ann Arbor, Michigan, USA \\ ${ }^{2}$ Physical Medicine and Rehabilitation Service, Veterans Affairs Medical Center, \\ 2215 Fuller Rd., Ann Arbor, Michigan 48105, USA \\ ${ }^{3}$ Department of Environmental Health Sciences, School of Public Health, University \\ of Michigan, Ann Arbor, Michigan, USA \\ ${ }^{4}$ Center for Ergonomics, School of Engineering, University of Michigan, \\ Ann Arbor, Michigan, USA
}

Accepted 1 June 2001

Carpal tunnel syndrome (CTS) has been identified as the most common type of upper extremity peripheral neuropathy. ${ }^{1,7}$ It is a known cause of work disability, with an estimated direct cost of $\$ 1$ billion per year. ${ }^{12}$ In an effort to avoid future medical costs, some industry employers utilize nerve conduction testing for pre-employment screening. ${ }^{2,3,14}$ A premise of this testing is that people with asymptomatic median mononeuropathy are more likely to develop CTS in the future than are those with normal test results. The proposed benefit of this practice is that prospective employees deemed to be a higher risk based on nerve conduction results will be placed in

\footnotetext{
Abbreviations: BMI, body mass index; CTS, carpal tunnel syndrome; EEOC, Equal Employment Opportunity Commission

Key words: carpal tunnel syndrome; epidemiology; median nerve; occupational medicine

Correspondence to: R.A. Werner at the Veterans Affairs Medical Center; e-mail: rawerner@umich.edu

(c) 2001 John Wiley \& Sons, Inc.
}

lower-risk jobs. In addition, these employees may be turned down for employment based on the test results, regardless of symptom status or physical examination results., ${ }^{2,3}$ Recent litigation results have upheld this practice despite the Equal Employment Opportunity Commission (EEOC) contention that it was not based upon scientific data. ${ }^{5}$

The present study is an extension of that by Werner et al., ${ }^{16}$ which surveyed workers with asymptomatic median mononeuropathy after a mean follow-up of 17 months to determine what percentage developed symptoms consistent with CTS (numbness, tingling, burning, pain in the hand or fingers occurring three or more times or lasting more than 1 week) compared with a group of matched controls. Results showed that asymptomatic subjects with a median mononeuropathy were not at a higher risk of developing symptoms compared with asymptomatic subjects with a healthy median nerve during the follow-up period: $12 \%$ of cases compared with $10 \%$ 
in the control group $\left(\mathrm{X}^{2}=.12, P=.73\right)$. Another recent study followed industrial workers over an 11year time period and found a correlation between initial severity of nerve conduction slowing and the probability of developing CTS in the future. ${ }^{13}$ Those workers with the most severe nerve conduction abnormalities had a $30 \%$ risk of developing symptoms consistent with CTS, whereas workers with normal nerve conduction studies had a $10 \%$ chance of developing such symptoms. Despite this association, the majority $(>70 \%)$ of those in the study with the most severe conduction slowing at baseline did not have symptoms of CTS after 11 years.

The purpose of the present study was to determine whether asymptomatic workers with or without median mononeuropathy develop symptoms consistent with CTS over an extended period of time and what other factors may influence the onset of CTS symptoms.

\section{MATERIALS AND METHODS}

This was a continuation of a previous prospective study of workers at five different sites. ${ }^{16}$ Cases were defined as asymptomatic workers with electrodiagnostic findings of a median mononeuropathy in either hand from a comparison of peak latencies of median and ulnar sensory nerve action potentials. A relative prolongation of $0.5 \mathrm{~ms}$ of the median sensory response was defined as abnormal. Controls were asymptomatic workers with normal nerve conduction studies in both hands matched by age, sex, and job site. Each job was rated on a scale of 1 to 10 in terms of frequency of hand repetition. ${ }^{11}$ Normal nerve conduction was defined as a median to ulnar sensory response latency (to peak) difference of 0.2 ms with both the median and ulnar absolute latencies within the normal range (median sensory peak $\leq 3.7 \mathrm{~ms}$ and ulnar sensory peak $\leq 3.5 \mathrm{~ms}$ ).

Electrodiagnostic studies of the median and sensory nerves were conducted bilaterally with the techniques described by Kimura. ${ }^{10}$ The tests were performed with antidromic supramaximal stimulation, a distance of $14 \mathrm{~cm}$, and ring-recording electrodes placed around digits 2 and 5. A standard distance of $3 \mathrm{~cm}$ between electrodes was used. Hand temperature was recorded, and the hand was warmed if the midpalmar temperature was below $32^{\circ} \mathrm{C}$. All studies were performed by a certified electromyographer and/or a certified electrodiagnostic technician on a Teca TD 20 machine (Teca, Pleasantville, New York). The sensory latency to peak, sensory response amplitude, and take-off latency were recorded for each sensory nerve.

The sites included an automobile parts manufac- turer, a spark plug manufacturer, a paper container manufacturer, and an insurance company (clerical staff). ${ }^{6}$ The follow-up consisted of a mailed questionnaire that included a hand diagram. If the workers had symptoms of pain, numbness, tingling or paresthesias in the hand or the fingers that lasted for more than 1 week or recurred at least three times, they filled out the hand diagram. Workers at all five sites were contacted through the mail. In addition, at four of the five sites, we attempted to contact workers directly to participate in a more extensive screening that included a physical examination as well as repeat nerve conduction studies. The fifth site had too much personnel turnover to make the on-site screening feasible; these workers were contacted via post only. Workers still employed by two of the companies (one manufacturing and one clerical) were tested on-site. Workers no longer employed by the same company were screened at an off-site location. Subjects from the other two companies were also seen off-site. Data on workers who did not participate in the follow-up screenings were collected via a posted symptom questionnaire in which the patient selfreported symptoms of numbness, tingling, burning, or pain in the hand or fingers that lasted for more than 1 week or occurred three or more times in the past year. The posted questionnaire contained questions identical to those used in the initial questionnaire, described in previous publications. ${ }^{6}$ If the worker did not return the questionnaire, telephone contact was attempted.

Subjects signed a written consent form that was approved by our institution's review board, and each subject completed an initial symptoms questionnaire. Age, sex, and medical history were selfreported in the questionnaire.

Workers who reported symptoms of numbness, tingling, burning, or pain were asked to shade in a hand diagram ${ }^{9}$ and to answer questions regarding frequency and length of episodes, treatment, change in work activity, and functional status. To be classified as positive, the worker had to complain of symptoms in the hand that had originally been found to have a median mononeuropathy. The hand diagrams were scored independently by two physicians using the 0-3 rating system described previously. $6,8,9$ Differences in ratings were resolved by consensus. If the subject shaded in any portion of the palmar side of digits 1, 2, or 3, this was considered positive.

The statistical analyses were performed with Stata (Stata Corp., College Station, Texas). Student's $t$ tests were used to compare the means of demographic variables (age, body mass index [BMI], months of follow-up), repetition levels, and electro- 
physiologic variables between responders and nonresponders as well as workers with and without follow-up symptoms. Chi-squared tests were used to compare the percentage of subjects with and without median mononeuropathy who had symptoms in the follow-up period; we did not use a matched-pair analysis, as we included all responders in the analysis. No cases were dropped, even if the matched worker did not respond. The analysis was completed using both a $0.5-\mathrm{ms}$ and $0.8-\mathrm{ms}$ prolongation in the peak latency of the median compared with the ulnar sensory response to define a median mononeuropathy. Backwards stepwise logistic regression was performed with presence or absence of symptoms at follow-up as the dependent variable and demographic factors (age, sex, months of follow-up, hand dominance) as well as electrophysiologic and anthropometric variables and repetition levels as the independent variables. All values are reported as a mean $(\mathrm{SD})$.

\section{RESULTS}

Of the original cases and controls, $70 \%(n=106)$ responded to the posted questionnaire or participated in the follow-up screening. Of the 45 subjects who did not participate, 3 were deceased, 15 did not respond, and neither phone nor current address was available for the remaining 27 subjects. Excluding those subjects lost to follow-up, there was an $88 \%$ response rate. All subjects with follow-up data are described in Table 1. The mean length of time of follow-up was 70 months (range, 56-94 months).

The mean \pm SD age, at the time of follow-up, among all subjects completing the study was $47 \pm 9$ years (range, $27-70$ years); $65 \%$ were men. The subjects who did not complete the study did not differ from those who did, with regards to age, sex, hand dominance, repetition level, or electrophysiologic variables. The subjects who did not complete the study tended to have an earlier initial study compared with subjects who did complete the study (73 \pm 16 versus $67 \pm 11 ; P=.005)$. Among subjects who did complete the study, age, prevalence of righthand dominance, months of follow-up, and repetition level did not differ between cases and controls. The BMI $\left(\mathrm{kg} / \mathrm{m}^{2}\right)$ was statistically higher in the cases $(29.9 \pm 5.8$ versus $27.8 \pm 4.3 ; P=.03$ [Table 1$])$, and there was a higher percentage of men among cases compared with controls $(75 \%$ versus $56 \% ; P=.04)$.

Among the 106 subjects who did complete the study, 15 reported persistent or repeated symptoms of numbness, tingling, burning, or pain in any fingers in the median distribution during the year prior to follow-up. All cases had symptoms in a hand that was initially found to have a median mononeuropathy. In $23 \%$ of the cases (12 of 52), symptoms developed, compared with $6 \%$ of controls ( 3 of 54 ), $\mathrm{X}^{2}=$ $6.6 ; P=.01$. Table 2 shows the percentage of workers who reported any symptoms in the follow-up period, stratified by presence or absence of a median mononeuropathy. When a subset of cases with a medianulnar latency difference of $0.8 \mathrm{~ms}$ was analyzed, $33 \%$ of the cases ( 8 of 24) developed symptoms compared with $6 \%, \mathrm{X}^{2}=10.6 ; P=0.001$. The same relationship held if the presence of nocturnal symptoms were added to the definition of new symptoms.

Among subjects who did complete the study, there was no difference in age, sex, hand dominance, repetition level (at baseline), or follow-up time between those who reported symptoms and those who did not report symptoms (Table 3). Subjects who reported symptoms tended to have a higher BMI at baseline than those without symptoms (31.0 versus 28.5; Student's $t=1.8 ; P=.08$ ). There

Table 1. Demographic factors and electrophysiologic variables stratified by cases (positive median mononeuropathy at baseline) and controls (mean $\pm \mathrm{SD}$ ).

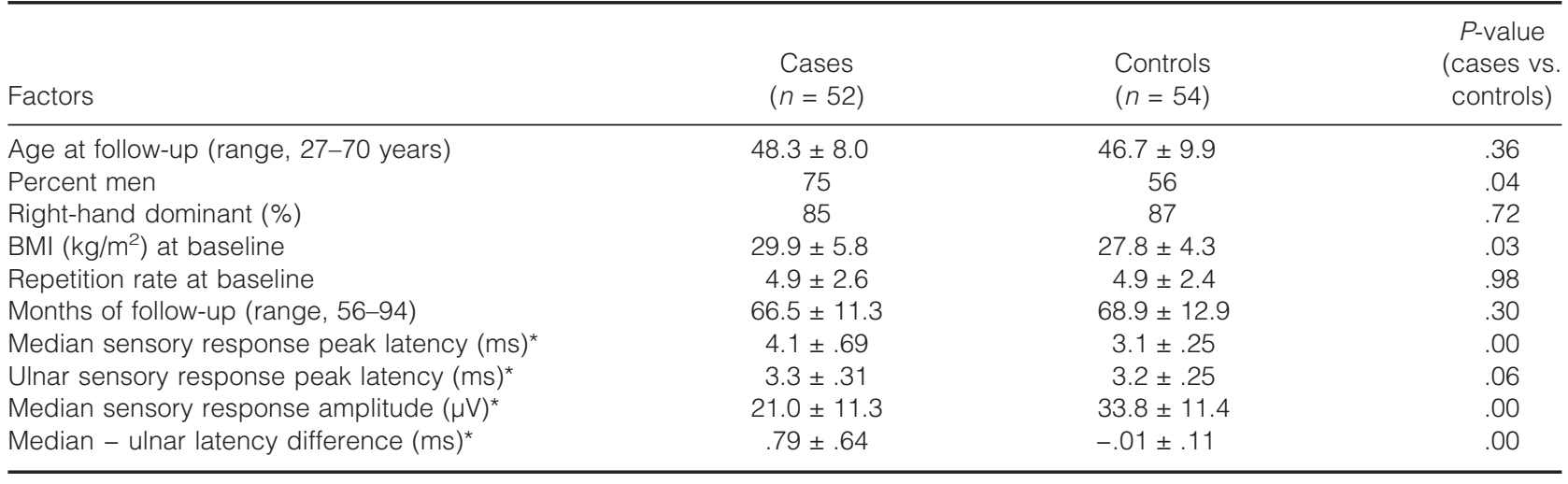

${ }^{\star}$ Electrophysiologic data are from the dominant hand. 
Table 2. Workers with positive hand diagram for CTS in the follow-up period stratified by presence or absence of a median mononeuropathy (defined by 0.5 -ms and 0.8-ms difference between median and ulnar sensory peak latencies).

Follow-up

symptoms in Cases Cases

hands $\quad(0.5-\mathrm{ms} \quad(0.8-\mathrm{ms}$

\begin{tabular}{lcccr} 
or fingers & difference) & difference) & Controls & Total \\
\hline Absent $n(\%)$ & $40(77)^{\star}$ & $21(72) \dagger$ & $51(94)$ & $91(86)$ \\
Present $n(\%)$ & $12(23)^{\star}$ & $8(28)^{\dagger}$ & $3(6)$ & $15(12)$ \\
Totals & 52 & 29 & 54 & 106
\end{tabular}

${ }^{*} X^{2}=6.7 ; P=.010$

$+X^{2}=10.6, P=.001$

was a significant difference in subjects with symptoms and those without for median-ulnar latency difference $(.83 \pm .97$ versus $.31 \pm .48$; Student's $t=$ 3.3; $P=.001)$ and median nerve peak latency $(4.1 \pm$ 1.0 versus $3.5 \pm .39$, Student's $t=2.96 ; P=.004$ ).

A backward stepwise logistic regression model of responders including demographic, electrophysiologic, and ergonomic factors demonstrated that age, hand repetition level, and history of a more severe median mononeuropathy were significant risk factors in the model when controlling for other variables (pseudo $R^{2}=.18 ; P=.0014$ ). Workers older than 46 years at baseline were 4.7 times more likely to report onset of symptoms consistent with CTS than were younger workers $(P=.02)$. Those with a more severe median mononeuropathy at baseline (using the criteria of the median sensory response latency of $.8 \mathrm{~ms}$ compared with the ulnar sensory response latency) were 3.8 times more likely to have positive symptoms $(P=.01)$. The BMI at baseline, sex, months of follow-up, and the less restrictive definition of a median mononeuropathy (prolonged median sensory response latency of $0.5 \mathrm{~ms}$ compared with the ulnar sensory response latency) did not contribute to the model.
A stratified analysis of only workers with a high repetition rating $(>6.0)$ showed a similar relationship with age and severity of median nerve conduction slowing, with only these factors contributing to the model for predicting development of hand and finger symptoms. When the data were stratified by sex, median sensory response amplitude was a significant factor. Men with a baseline response amplitude of greater than $20 \mu \mathrm{V}$ had less than a $3 \%$ risk of developing CTS symptoms, whereas those men with a small-amplitude response had a $26 \%$ likelihood of developing symptoms (Table 4).

The analysis of the electrodiagnostic measures of workers who had nerve conduction studies at the initial evaluation as well as at follow-up is presented in Table 5. In general, cases (workers with an abnormal median nerve at the initial screening) did not change significantly over the 6 years of follow-up. However, controls did have a small but significant change in median nerve function over time. The median sensory latency was slower in the controls, but the ulnar sensory latency did not change. The difference between the median and ulnar sensory latencies also became more prolonged over time within the control group (baseline $=.001 \mathrm{~ms}$ versus follow-up $=.11 \mathrm{~ms} ; P=.003)$. There was a high correlation between the initial and follow-up latency differences (median - ulnar sensory peak latency), with a correlation coefficient of 0.83 . Table 5 stratifies the data based upon their presentation of symptoms. All subjects were asymptomatic at the onset of the study. Those workers who became symptomatic showed no change in median sensory function, whereas workers who did not become symptomatic had a slight prolongation of the median sensory latency over time; this was not influenced by whether they were originally a case or a control subject. Among controls who had a change in the median to ulnar sensory latencies, such that they now had a prolonged median

\begin{tabular}{|c|c|c|c|c|}
\hline & $\begin{array}{c}\text { Subjects with } \\
\text { symptoms } \\
n=15\end{array}$ & $\begin{array}{l}\text { Subjects without } \\
\text { symptoms } \\
n=91\end{array}$ & T score & $P$ value \\
\hline Age $(y r)$ & $50.8( \pm 7.7)$ & $46.9( \pm 9.2)$ & 1.55 & 0.13 \\
\hline No. $(\%)$ men & $6(40)$ & $31(34)$ & 0.20 & 0.655 \\
\hline No. (\%) right-hand dominant & $12(80)$ & $79(87)$ & 0.49 & 0.483 \\
\hline Baseline median sensory peak latency $(\mathrm{ms})^{*}$ & $4.1( \pm 1.0)$ & $3.5( \pm .59)$ & 2.96 & 0.004 \\
\hline Baseline ulnar sensory peak latency $(\mathrm{ms})^{*}$ & $3.2( \pm .32)$ & $3.2( \pm .28)$ & 0.42 & 0.68 \\
\hline Baseline median - ulnar latency difference $(\mathrm{ms})^{*}$ & $.83( \pm .97)$ & $.31( \pm .48)$ & 3.3 & 0.001 \\
\hline BMI at baseline $\left(\mathrm{kg} / \mathrm{m}^{2}\right)$ & $31.0( \pm 5.2)$ & $28.5( \pm 5.1)$ & 1.8 & 0.08 \\
\hline Repetition rate at baseline & $5.7( \pm 2.7)$ & $4.7( \pm 2.4)$ & 1.3 & 0.20 \\
\hline Months of follow-up & $67.5( \pm 9.9)$ & $67.8( \pm 12.5)$ & -0.09 & 0.93 \\
\hline
\end{tabular}

${ }^{*}$ Electrophysiologic data are from the dominant hand. 
sensory latency, none of the six subjects had symptoms associated with the change in median nerve function, i.e., none of the workers who developed a prolonged median sensory response developed CTS.

\section{DISCUSSION}

The present study is a continuation of a previously published one $^{16}$ that found no increased risk for the development of CTS symptoms based upon initial nerve conduction findings. The original study had a mean 17-month follow-up period. After a mean follow-up of 70 months, our current findings are different. After approximately 6 years, there is an increased risk of developing CTS symptoms if the worker had an abnormal finding earlier. In addition, the more abnormal the median nerve function at baseline, the more likely the risk of developing symptoms consistent with CTS. These findings are in accordance with those in the study of Nathan et al., ${ }^{13}$ which had an 11-year follow-up of industrial workers. In each study, approximately $25 \%$ of asymptomatic workers having median mononeuropathy went on to develop symptoms of CTS. This is not surprising given that prolongation of the median sensory nerve is one of the hallmarks of CTS. The relationship is statistically significant, but the issue of nerve conduction studies as a screening device is still unclear. The vast majority of workers with an abnormal median sensory latency at baseline did not go on to develop symptoms of CTS. In our previous paper, we concluded that electrodiagnostic screening was definitely not recommended. This study supports the usefulness of nerve conduction studies for screening in the theoretical sense, but it has limited practical value. Most workers who would be screened are going to have normal median nerve function, and of the $20 \%$ who have an abnormal finding, only $25 \%$ will go on to develop symptoms over time. The finding among men that a relatively preserved median sensory response amplitude places the worker at lower risk than does a small-amplitude response of the median nerve may help refine a screening process.
Table 4. Male workers with hand or finger symptoms in the

follow-up period stratified by median sensory response amplitude (dominant hand) at baseline.

\begin{tabular}{lccc}
\hline & $\begin{array}{c}\text { No symptoms } \\
\text { at follow-up } \\
(\%)\end{array}$ & $\begin{array}{c}\text { Symptoms } \\
\text { at follow-up } \\
(\%)\end{array}$ & Total \\
\hline $\begin{array}{l}\text { Median sensory response } \\
\quad \text { amplitude } \leq 20 \mu \mathrm{V}\end{array}$ & $23(74)$ & $8(26)$ & 31 \\
$\begin{array}{l}\text { Median sensory response } \\
\quad \text { amplitude }>20 \mu \mathrm{V}\end{array}$ & $37(97)$ & $1(3)$ & 38 \\
$\begin{array}{l}\text { Total } \\
\text { Tol }\end{array}$ & $60(87)$ & $9(13)$ & 69 \\
\hline
\end{tabular}

Pearson $\chi^{2}=8.08 ; \mathrm{P}=.004$

The other risk factors for the development of CTS include older age, higher BMI, and more repetitive jobs. Age is a well-established risk factor for nerve entrapment. With advancing age, peripheral nerve axons are lost. If the total number of axons declines, the loss of a few of the surviving axons results in a more profound impairment. Interestingly, the literature has demonstrated progressive impairment of all nerves with age, whereas the current study demonstrates that the ulnar nerve is relatively spared over the 6 years, in contrast to median nerve. This suggests that intensive activity of the hand may have a greater effect on the median nerve than on the ulnar nerve.

Additionally, the finding that higher handintensive work is associated with a higher risk for developing CTS is not new. We found the same relationship in our earlier studies, ${ }^{11,16}$ and the National Institute of Occupational Safety and Health reached the same conclusion in its review of the literature. ${ }^{4}$ Workers with a baseline prolongation of the median sensory response had a higher BMI, which is consistent with the reported literature, ${ }^{15}$ but this factor did not significantly influence the development of future CTS symptoms.

The follow-up nerve conduction data demonstrate that change in the median sensory distal latency did not correlate with the development of symptoms. The median sensory distal latency did tend to increase over time among individuals who

Table 5. Comparison of electrophysiologic factors (mean \pm SD) in subjects with baseline and follow-up nerve conduction testing, stratified by workers with and without symptoms at follow-up (dominant hand).

\begin{tabular}{|c|c|c|c|c|c|c|}
\hline & \multicolumn{2}{|c|}{ Symptomatic at follow-up } & \multirow[b]{2}{*}{$P$ value } & \multicolumn{2}{|c|}{ Asymptomatic at follow-up } & \multirow[b]{2}{*}{$P$ value } \\
\hline & $\begin{array}{c}\text { Baseline } \\
n=8\end{array}$ & $\begin{array}{c}\text { Follow-up } \\
n=8\end{array}$ & & $\begin{array}{c}\text { Baseline } \\
n=55\end{array}$ & $\begin{array}{c}\text { Follow-up } \\
n=55\end{array}$ & \\
\hline Median sensory peak latency (ms) & $4.1 \pm 1.3$ & $4.2 \pm 1.4$ & 0.59 & $3.4 \pm .45$ & $3.5 \pm .51$ & 0.25 \\
\hline Ulnar sensory peak latency (ms) & $3.3 \pm .33$ & $3.3 \pm .27$ & 0.87 & $3.2 \pm .26$ & $3.2 \pm .25$ & 0.57 \\
\hline Median sensory amplitude $(\mu \mathrm{V})$ & $20.4 \pm 8.9$ & $21.4 \pm 11.5$ & 0.94 & $28.8 \pm 10.6$ & $27.9 \pm 13.0$ & 0.40 \\
\hline Median - ulnar peak latency difference (ms) & $.85 \pm 1.2$ & $.90 \pm 1.3$ & 0.71 & $.21 \pm .38$ & $.33 \pm .50$ & 0.02 \\
\hline
\end{tabular}


did not develop symptoms. By contrast, among those who did develop symptoms, there was essentially no change. Among those workers who developed a significant prolongation of the median sensory distal latency over time, none reported symptoms. This challenges our concepts as to why workers become symptomatic with CTS. Not all individuals with a median mononeuropathy report symptoms.

In conclusion, we have demonstrated that asymptomatic workers with a history of a prolongation in latency of the sensory responses of the median nerve are more likely to develop symptoms consistent with CTS. Despite this relationship, the vast majority of asymptomatic workers with a median mononeuropathy will not develop CTS, and changes in median nerve conduction over time do not correlate with the development of symptoms.

The opinions contained in this publication are those of the grantee and do not necessarily reflect those of the United States Department of Education. Support for this research is provided by the National Institute on Disability and Rehabilitation Research of the United States Department of Education, grant no. H133E980007.

\section{REFERENCES}

1. Anonymous. CTD clinic: growing nerve-test industry sparks questions about efficacy of the ADA. CTD News 1993;2:8-9.

2. Anonymous. Diagnosis of the carpal tunnel syndrome. Lancet 1985;1:854-855.

3. Anonymous. Preplacement test for CTDs challenged. CTD News 1995;4:1-7.

4. Bernard B, editor. Musculoskeletal disorders and workplace factors: a critical review of epidemiologic evidence for workrelated musculoskeletal disorders of the neck, upper extremity and low back. Washington DC, NIOSH publication no. 97-141;1997.
5. EEOC v. Rockwell International Corporation, no.95C-3824 (N.D. Ill), June 30, 1995.

6. Franzblau A, Werner RA, Albers JW, Olinski D, Johnston E. Workplace surveillance for carpal tunnel syndrome using hand diagrams. J Occup Rehabil 1994;4:185-98.

7. Jablecki CK, Andary MT, So YT, Wilkins DE, Williams FH. Literature review of the usefulness of nerve conduction studies and electromyography for the evaluation of patients with carpal tunnel syndrome. Muscle Nerve 1993;16:1392-1414.

8. Katz JN, Stirrat CR. A self-administered hand diagram for the diagnosis of carpal tunnel syndrome. J Hand Surg 1990;15A: 360-363.

9. Katz JN, Stirrat CR, Larson MG, Fossel AH, Eaton HM, Liang MH. A self-administered hand diagram for the diagnosis and epidemiologic study of carpal tunnel syndrome. J Rheumatol 1990;17:1495-1498.

10. Kimura J. Electrodiagnosis in diseases of nerve and muscle: principles and practice. Philadelphia: FA Davis; 1983. p 106-111.

11. Latko WA, Armstrong TJ, Franzblau A, Ulin SS, Werner RA, Albers JW. A cross-sectional study of the relationship between repetitive work and the prevalence of upper limb musculoskeletal disorders. Am J Ind Med 1999;36:248-259.

12. Levine DW, Simmons BP, Koris MJ, Daltroy LH, Hohl GG, Fossel AH, Katz JN. A self-administered questionnaire for the assessment of severity of symptoms and functional status in carpal tunnel syndrome. J Bone Joint Surg Am 1993;75: 1585-1592.

13. Nathan PA, Keniston RC, Myers LD, Meadows KD, Lockwood RS. Natural history of median nerve sensory conduction in industry: relationship to symptoms and carpal tunnel syndrome in 558 hands over 11 years. Muscle Nerve 1998;21: 711-721.

14. Pruitt, RH. Preplacement evaluation: thriving within the ADA guidelines. Am Assoc Occup Health Nurses J 1995;43:124-30.

15. Werner RA, Albers JW, Franzblau A, Armstrong TJ. The influence of body mass index and work activity in determining the prevalence of median mononeuropathy at the wrist. Occup Environ Med 1997;54:268-271.

16. Werner RA, Franzblau A, Albers JW, Buchele H, Armstrong TJ. Use of screening nerve conduction studies for predicting future carpal tunnel syndrome. Occup Environ Med 1997;54: 96-100. 